\title{
Research on Spatial Heterogeneity Impacts of Regional Income Gap and Urbanization on Crime Rate: An Empirical Study Based on Provincial Panel Data in China
}

\author{
Shunhui Li ${ }^{\mathrm{a}}$, Qiubi Sun \\ School of Economics and Management, Fuzhou University, Fuzhou 350116, PR China \\ asunfast@foxmail.com, bsunqiubi@126.com
}

Keywords: Crime rate; Regional income gap; Urbanization; Spatial impacts

\begin{abstract}
Based on the panel data of 31 provinces and cities in China from 2000 to 2015, this paper uses spatial econometric models to explore the spatial heterogeneity impacts of regional income gap and urbanization on crime rate. The research finds that, the impacts of regional income gap and urbanization on crime rate show obvious spatial non-stationarity and massive feature. Among them, the contributions of regional income gap to crime rate in eastern, central and western regions respectively account for $7.96 \%, 21.13 \%$ and $73.05 \%$ of the total contribution, while the contributions of urbanization respectively account for $43.28 \%$, $48.97 \%$ and $7.75 \%$. This paper finally puts forward some policy suggestions on promoting the coordinated development of urbanization and crime control.
\end{abstract}

\section{Introduction}

Since the reform and opening-up, great achievements have been made in China's economic construction; China has been gradually transforming from a rural agricultural society to an urban industrial society; urbanization process speeds up the concentration of population into cities, and comes with continued increase of national income and effective improvement of living standard. However, in the meantime, China's crime rate is obviously on the rise. According to the data released in Law Yearbook of China, China's crime rate increased 8.3858 times from 55.65 to 522.3217 per 100,000 people between 1978 and 2015. Meanwhile, there is a trend of expansion for the regional income gap in China, which will definitely cause regional conflicts and contradictions, thereby inducing the occurrence of criminal activities and making the crime problem become a regional social problem. It is worth noting that, under the background of regional economic integration, regional economic activities and social activities will no longer exist in Islanded Mode, but show an interdependent relationship at the spatial level. Due to differences in historical and geographical, economic and cultural factors in different regions, such interdependence also shows certain heterogeneity. Therefore, regional criminal activity is not an internal event of an isolated kingdom, but a regional social problem. Nevertheless, most of the existing researches ignore the exploration for the impacts of regional income gap and urbanization on crime rate from the spatial dimension. Under this background, to explore the law of spatial effect of regional income gap and urbanization level on crime rate, will be able to provide valuable knowledge and reference for the design and formulation of China's regional crime control policy.

With the development of GIS technology and spatial econometrics, some scholars begin to study crime problem from the spatial dimension. Sparks (2001) and Cracolici (2009) respectively made the exploratory analysis on the spatial distribution characteristics of the crime rate of regions like Texas of America and Italian regions by adopting GIS technology. Scholars, such as FengJian (2012), Zhong Haidong (2013) and Liu Daqian (2014), respectively conducted the research on the spatial distribution characteristics of urban crime of Beijing, Changchun and Shanghai in China. These studies are conducted mainly based on cross-sectional data to explore the spatial characteristics of crime rate, while the research on the spatial impacts of regional income gap and urbanization level on 
crime rate from the perspective of spatial dependence and heterogeneity is still scarce. Yan Xiaobing (2013) adopted the Spatial Lag Model (SLM) to analyze the relationship between urbanization, income gap (regional, industrial and urban-rural) and crime rate, but such model can only reflect the spatial effects of crime rate itself and cannot describe the law of effect of variables (such as urbanization level and income gap of surrounding regions, etc.) on local crime rate. Furthermore, Yan Xiaobing (2013) also adopted GWR model to analyze the spatial heterogeneity impacts of population mobility and urban-rural income gap on crime rate, but did not include the urbanization and the regional income gap in the scope of research considerations, therefore it is unable to reveal the law of spatial heterogeneity impacts of urbanization and regional income gap on crime rate. Thus, the influencing mechanism and the function law of the three (urbanization, income gap and crime rate) in spatial dimension are not fully revealed, and to explore the functional relations between the three in spatial dimension is still a frontier research topic in the field of economic crimes.

To further reveal the functional mechanism of urbanization and regional income gap on crime rate, this paper will adopt the Geographically Weighted Regression (GWR) model mainly based on the studies of scholars to explore the spatial non-stationarity impacts of regional income gap and urbanization level of China's 31 provinces and cities on the crime rate.

\section{Data Description and Theoretical Model}

\subsection{Variable Selection and Data Description}

Based on reference to variable selection in previous studies, and according to the data availability and the research emphasis, the variables selected in this paper mainly include: crime rate, floating population, economic growth, unemployment rate, degree of education, urbanization rate, regional income gap and economic opening rate, among which, the economic opening rate is an exogenous variable. The definitions and the statistical properties of variables are shown in Table 1.

Table 1 Definitions and Descriptive Statistics of Variables

\begin{tabular}{|c|c|c|c|c|}
\hline Variables & Definitions & $\begin{array}{l}\text { Mean } \\
\text { Value }\end{array}$ & $\begin{array}{l}\text { Standard } \\
\text { Deviation }\end{array}$ & Value \\
\hline crime & $\begin{array}{l}\text { Crime rate: refers to the number of people approved to be arrested per } \\
100,000 \text { people }\end{array}$ & 6.8245 & 2.4611 & 496 \\
\hline flp & $\begin{array}{l}\text { Floating population: refers to the proportion of temporary population in } \\
\text { local permanent population }\end{array}$ & 7.7847 & 9.6636 & 496 \\
\hline gdp & Economic growth: refers to GDP growth per capita & 2.1367 & 1.8087 & 496 \\
\hline urban & $\begin{array}{l}\text { Urbanization rate: refers to the ratio of local total urban population to the } \\
\text { total population }\end{array}$ & 0.4332 & 0.1622 & 496 \\
\hline $\begin{array}{l}\text { unemploy } \\
\text { menrt }\end{array}$ & Unemployment rate: refers to the registered urban unemployment rate & 3.5715 & 0.7488 & 496 \\
\hline education & $\begin{array}{l}\text { Degree of education: refers to the number of college students per 10,000 } \\
\text { people }\end{array}$ & 48.6309 & 40.8867 & 496 \\
\hline ingap & $\begin{array}{l}\text { Regional income gap: refers to the difference between local consumption } \\
\text { expenditures per capita and national consumption expenditures per capita }\end{array}$ & 0.00379 & 0.4184 & 496 \\
\hline open & $\begin{array}{l}\text { Economic opening rate: refers to the logarithmic total export-import } \\
\text { volume converted according to the exchange rate of the U.S. Dollar } \\
\text { against RMB }\end{array}$ & 6.9168 & 0.8176 & 496 \\
\hline $\mathrm{W}$ & $\begin{array}{l}\text { Spatial weight matrix: refers to the spatial neighborhood relation }{ }^{[10]} \\
\text { constructed according to Queen Rule }\end{array}$ & ----- & ---- & ---- \\
\hline
\end{tabular}

Note 1: the data required for the variables above is mainly from Law Yearbook of China, Procuratorial Yearbook of China and Compilation of Statistics on National Temporary Population between 2000 and 2015.

\subsection{GWR modelling}

Take the crime rate as dependent variable, floating population and regional income gap, economic growth and urbanization level, unemployment rate and degree of education as independent variables, 
and the coordinate for area $i$ is assumed to be $\left(\mu_{i}, v_{i}\right)$, then the GWR model for influencing factors of crime rate in China's 31 provinces and cities can be established as Eq.1:

$$
\begin{aligned}
& y_{i}=\beta_{0}\left(\mu_{i}, v_{i}\right)+\sum_{j=1, k} \beta_{1}\left(\mu_{i}, v_{i}\right) x_{i j}(\text { flp })+\sum_{j=1, k} \beta_{2}\left(\mu_{i}, v_{i}\right) x_{i j}(\text { gdp }) \\
& +\sum_{j=1, k} \beta_{3}\left(\mu_{i}, v_{i}\right) x_{i j}(\text { urban })+\sum_{j=1, k} \beta_{4}\left(\mu_{i}, v_{i}\right) x_{i j}(\text { unemployment }) \\
& +\sum_{j=1, k} \beta_{5}\left(\mu_{i}, v_{i}\right) x_{i j}(\text { education })+\sum_{j=1, k} \beta_{6}\left(\mu_{i}, v_{i}\right) x_{i j}(\text { ingap })+\varepsilon_{i}
\end{aligned}
$$

\section{Empirical Analysis}

Due to differences in geographical conditions and historical culture, social conventions and economic environment in different regions, there is obvious difference in conditions such as floating population, urbanization, degree of education and economic development, so that there is also difference in the flexibility of effect of various factors on crime rate, that is to say, there is non-stationarity for the impacts of these factors in spatial dimension. To further reflect the spatial heterogeneity impacts of these factors on crime rate, it is required to adopt the GWR model proposed by Brunsdon, Fotheringham and Charlton (1996) to further explore the spatial heterogeneity impacts of various factors on crime rate. The estimates of GWR model for crime rate of China's 31 provinces and cities on floating population, regional income gap, economic growth, urbanization level, unemployment rate and degree of education are shown in Figure. 1.

In Figure. 1, the estimated coefficient of variable crime on ingap is generally on the rise from eastern regions to western regions (Figure. 1(1)). More specifically, the flexibility of effect of regional income gap on crime rate in eastern regions is relatively low (sequence numbers 1-11), with the mean value of 0.1946 , followed by the flexibility in central regions (sequence numbers 12-19) with the mean value of 0.7073 , while the flexibility in western regions (sequence numbers 20-31) is the highest with the mean value of 2.4451, which is closely related to regional income gap at this stage in China. The internal income gaps in eastern, central and western regions are relatively low, but the inter-regional horizontal income gap is large. Take the year 2015 for example, the income per capita in eastern regions is respectively 1.6287 times and 1.8260 times that of central and western regions, and the expansion of regional income gap will cause the tension between regions, which will easily lead to a contrary or contradictory state between regions and thereby induce regional crime problem. According to Figure. 1(6), the effect of urbanization on crime rate is generally positive, and the flexibility of effect of urbanization on crime rate in spatial distribution shows S-shaped distribution from East to West. From the perspective of regional horizontal comparison, the flexibility of effect of urbanization level on crime rate in eastern regions is closer to that in central regions, respectively with the mean values of 1.6440 and 1.8599; while the flexibility in western regions is the lowest, with the mean value of 0.2944 , and urbanization in some regions has an inhibited effect on crime rate, therefore the calculation results generally support the existing mainstream research conclusion. Some scholars point out that, there is inverted-U relation (Chen Chunliang, 2010) for the effect of urbanization on crime rate. However, the estimated coefficient in some regions, especially in some central and western regions, is negative. This indicates that, maybe there is not only inverted-U curvilinear relation for the effect of urbanization on crime rate, but also other curve forms, such as S-shaped curvilinear relation (Figure. 2) . 
(1). Estimated coefficient of crime on ingap

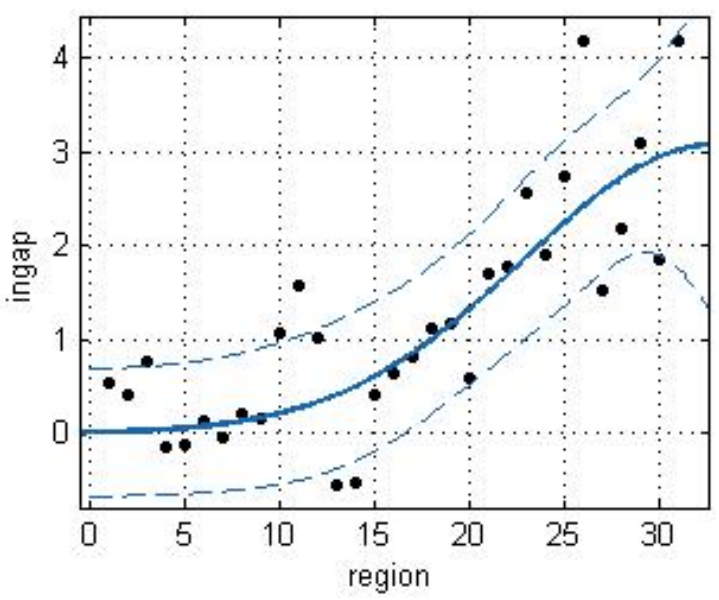

(3). Estimated coefficient of crime on gdp

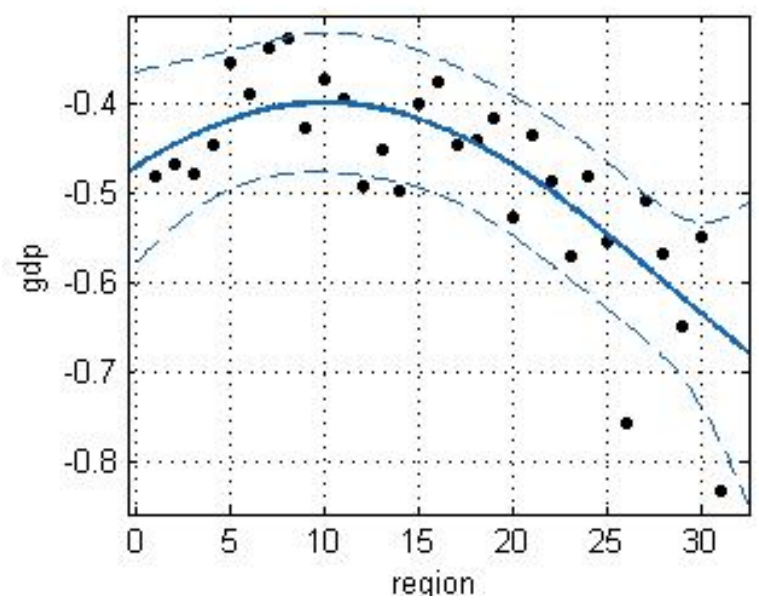

(5). Estimated coefficient of crime on unemployment

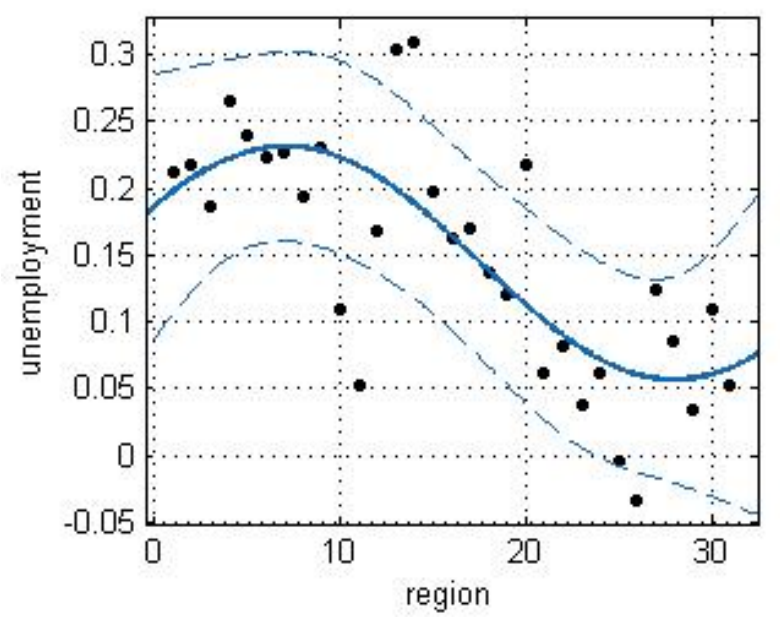

(2). Estimated coefficient of crime on flp

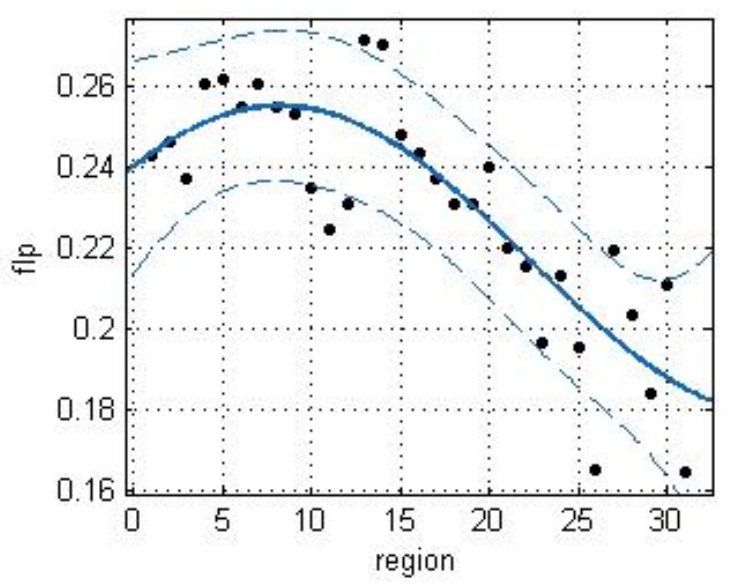

(4). Estimated coefficient of crime on education

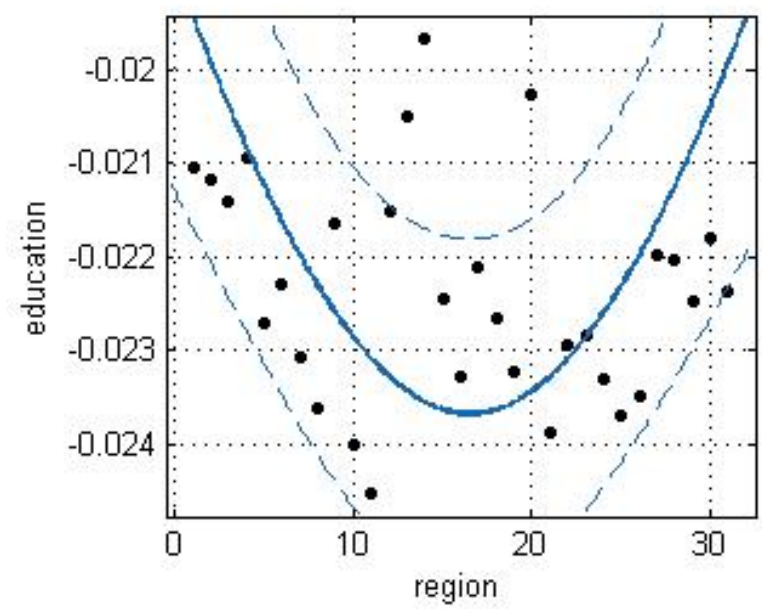

(6). Estimated coefficient of crime on urban

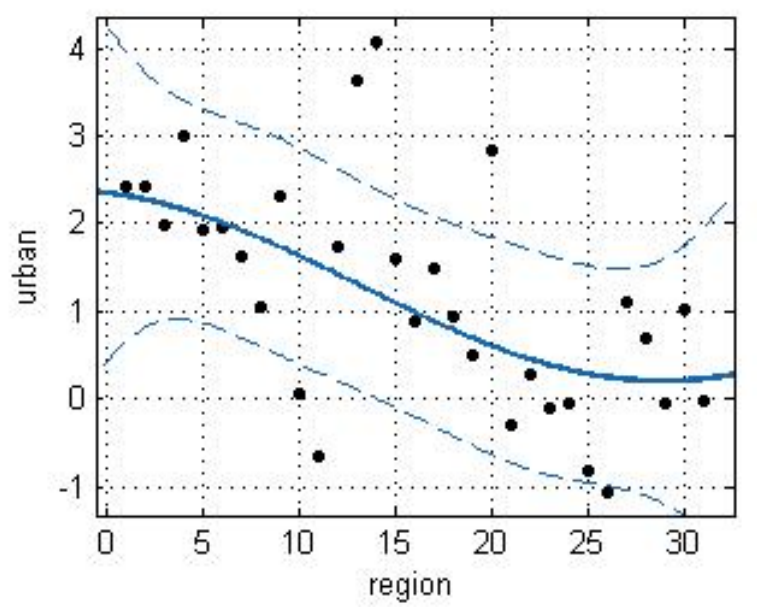

Figure. 1 Estimated Result Based on GWR Model

Note 2: the vertical coordinate in the subgraphs of Figure. 1 represents regression coefficient of crime rate for various variables, and sequence numbers 1-30 of horizontal coordinates are numbers in sequence of eastern, central and western provinces and cities provided in China Statistical Yearbook. Including, sequence numbers of eastern provinces and cities are 1-11, those of central provinces and cities are 12-19, and those of western provinces and cities are 20-31, specifically expressed as: 1-Beijing, 2-Tianjin, 3-Hebei, 4-Liaoning, 5-Shanghai, 6-Jiangsu, 7-Zhejiang, 8-Fujian, 9-Shandong, 10-Guangdong, 11-Hainan, 12-Shanxi, 13-Jilin, 14-Heilongjiang, 15-Anhui, 16-Jiangxi, 17-Henan, 18-Hubei, 19-Hunan, 20-Inner Mongolia, 21-Guangxi, 22-Chongqing, 23-Sichuan, 24-Guizhou, 
25-Yunnan, 26-Tibet, 27-Shaanxi, 28-Gansu, 29-Qinghai, 30-Ningxia and 31-Xinjiang.

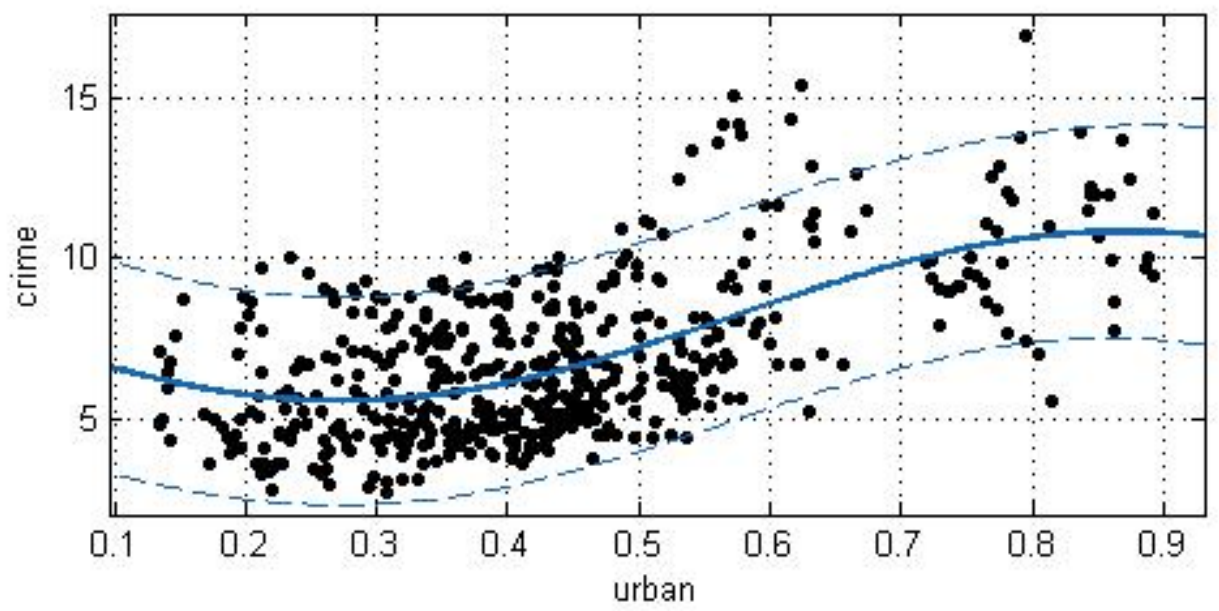

Figure. 2 Fitted Curve between crime and urban

The flexibility of spatial effect of other control variables on crime rate is also obtained here: (1) the flexibility of effect of floating population on crime rate in various regions is obviously positive, and the effect from East to West generally shows an inverted-U spatial distribution. This indicates that, the effect of floating population on crime rate in eastern regions is much larger than that in western regions; (2) the effect of unemployment rate on crime rate in various regions is generally positive, and shows " " type of spatial distribution. This distribution result shows that, the flexibility of effect of unemployment rate on crime rate in central and eastern regions is much larger than that in western regions; (3) the effects of economic growth and degree of education on crime rate in various regions are inhibited on a different level, and respectively show inverted-U and U-shaped spatial distributions. To be more specific, the inhibited effect of economic growth on crime rate in western regions is more obvious than those in eastern and central regions. Meanwhile, to increase the education investment in eastern, central and western regions and improve the degree of education in various regions (especially to improve the education degree of people in central and western regions), will be able to produce more obvious inhibited effect on crime rate.

\section{Conclusions and Enlightenment}

Based on the panel data of China's 31 provinces and cities from 2000 to 2015, this paper adopts the GWR model to explore the law of spatial effects of regional income gap and urbanization level on crime rate from the perspective of spatial non-stationarity and obtain a series of new conclusions: the effects of regional income gap and urbanization on crime rate show extremely obvious spatial non-stationarity and massive feature. Including, the contribution of regional income gap to crime rate in eastern regions is the lowest (accounting for $7.69 \%$ of the total contribution), followed by that in central regions (accounting for 21.13\%), and that in western regions is the highest (accounting for $73.05 \%)$. While the contribution of urbanization to crime rate in central regions is the highest (accounting for $48.97 \%$ of the total contribution), followed by that in eastern regions (accounting for 43.28\%), and that in western regions is the lowest (accounting for 7.75\%). Therefore, we can conclude that, to moderately narrow the income gap between western and eastern regions and improve the urbanization level of western regions, will be helpful to control the increase in crime rate in China on the whole.

By combining the research conclusions above, we can obtain the following aspects of policy enlightenment: (1) to construct well-established regional crime prevention and control system, and further control the spatial neighborhood effects and spatial spillover effects of criminal activities. Also, the construction of regional crime prevention and control system will be helpful to internalize the criminal activities, and to some extent compress the external space of criminal activities, so as to improve the controllability of spatial effects of criminal activities. (2) To speed up the economic 
development of underdeveloped regions and further narrow the income gap between regions (especially to further narrow the income gap between western and central regions, between underdeveloped and developed regions), will have a significant effect on crime control. (3) To moderately slow down or adjust the urbanization development of developed regions, and improve the urbanization level of underdeveloped regions. More precisely, the developed regions should focus on improving the quality of urbanization, to solve the "Peri-urbanization" problem at this stage, while the underdeveloped regions may moderately improve the speed of urbanization and turn to quality improvement until a certain level of urbanization is reached.

\section{Acknowledgements}

This work was financially supported by the Fujian Social Science Foundation (FJ2018C041).

\section{References}

[1] Chen Gang, Li Shu, Chen Yili. Research on Effects of Population Mobility on Crime Rate [J]. Chinese Journal of Population Science, 2009, 4:52-61. In Chinese.

[2] Anselin L, Cohen J, Cook D, et al. Spatial analyses of crime [J]. Criminal justice, 2000, 4(2): 213-262.

[3] Sparks C S. Violent crime in San Antonio, Texas: An application of spatial epidemiological methods [J]. Spatial and spatio-temporal epidemiology, 2011, 2(4): 301-309.

[4] Cracolici M F, Uberti T E. Geographical distribution of crime in Italian provinces: a spatial econometric analysis [J]. Jahrbuch für Regional wissenschaft, 2009, 29(1): 1-28.

[5] Feng Jian, Huang Linshan, Dong Ying, Song Leilei. Research on the Spatial-Temporal Characteristics and Mechanism of Urban Crime: A Case Study of Property Crime in Beijing [J]. Acta Geographica Sinica, 2012, 12: 1645-1656. In Chinese.

[6] Zhong Haidong, Wu Jianping, Yu Bailang, Wang Zhanhong. Study on the Spatial Pattern of Shanghai Crime Based upon GIS [J]. Journal of East China Normal University (Natural Science), 2013, 2:30-37. In Chinese.

[7] Liu Daqian, Song Wei, Xiu Chunliang. Spatial Analysis on Robbery, Forcible Seizure, Vehicle Theft and Burglary in Changchun [J]. Scientia Geographica Sinica, 2014, 11:1344-1352. In Chinese.

[8] Yan Xiaobing. Spatio-temporal Pattern of Crime Rates in China [J]. Scientia Geographica Sinica, 2013, 33(5): 529-537. In Chinese.

[9] Yan Xiaobing. Spatial non-stationarity of the factors affecting crime rate at province scale in China [J]. Progress in Geography, 2013, 7:1159-1166. In Chinese.

[10] LeSage J, Pace R K. Introduction to spatial econometrics [M]. CRC press, 2009.

[11] Brunsdon C, Fotheringham A S, Charlton M E. Geographically weighted regression: a method for exploring spatial nonstationarity [J]. Geographical analysis, 1996, 28(4): 281-298. 